UNIVERSIDADE ESTADUAL DE FEIRA DE SANTANA

Autorizada pelo Decreto Federal $\mathrm{n}^{\circ} 77.496$ de 27/04/76
Recredenciamento pelo Decreto ${ }^{\circ} 17.228$ de 25/11/2016

PPPG PRÓ-REITORIA DE PESQUISA E PÓS-GRADUAÇão

COORDENAÇÃO DE INICIAÇÃO CIENTÍFICA

XXIV SEMINÁRIO DE INICIAÇÃO CIENTÍFICA DA UEFS

SEMANA NACIONAL DE CIENTÍFICA E TECNOLÓGICA - 2020

\title{
A IMPLANTAÇÃO DO CENTRO INDUSTRIAL NORTE (CIN) EM FEIRA DE SANTANA E SUA IMPORTÂNCIA ATUAL PARA A DINÂMICA ECONÔMICA DO MUNICÍPIO.
}

\author{
$\underline{\text { Jacqueline de Jesus Bastos }}{ }^{1}$; Janio Santos ${ }^{2}$; \\ 1. Bolsista PROBIC/UEFS, Graduanda em Licenciatura de Geografia, Universidade Estadual de Feira de Santana, e- \\ mail: jack_fsabastos@hotmail.com \\ 2. Jânio Laurentino de Jesus Santos, Doutor em Geografia, Departamento de Ciências Humanas e Filosofia, \\ Universidade Estadual de Feira de Santana, e-mail: Janiosantos@yahoo.com.br
}

PALAVRAS-CHAVE: Indústria, Distrito Industrial, Reestruturação Produtiva.

\section{INTRODUÇÃO}

Ao tratar de industrialização, o tema liga-se diretamente à indústria. Porém, é importante entender que nem toda cidade que possui uma indústria passa e/ou passou por um processo de mudanças amplas. A industrialização é o crescimento da atividade industrial, com forças produtivas, que articula atividades diferentes e que possuem relações com várias empresas voltadas à produção de máquinas, à ampliação da tecnologia, o que provoca transformações na economia de um dado território.

O processo industrial em Feira de Santana começou a se fortalecer em 1970, quando foi implantado o Centro Industrial do Subaé (CIS), localizado no sul da cidade, no bairro Tomba. Todavia, ao decorrer dos anos, percebe-se um interesse em expandir essa industrialização para o norte de Feira de Santana, local que foi pouco explorado em pesquisas, até então, sendo exemplo dessa expansão as implantações das indústrias B.N Mascarenhas, Incomprel e das fábricas Avanço Distribuidora e Globalpark na BR 116 norte, entre a Universidade Estadual de Feira de Santana (UEFS) e o Distrito de Maria Quitéria, então área rural. Com a duplicação da BR-116 norte, houve maior visibilidade do local e certo interesse de urbanizá-lo, por ser uma localidade com um vasto campo pouco aproveitado, no âmbito dos interesses do capital produtivo, além de possuir um recurso hídrico, uma lagoa.

Mediante a essa problemática, busca-se com essa pesquisa entender a expansão da atividade industrial para o norte do município de Feira de Santana, no sentido de verificar os impactos da implantação de um novo Centro Industrial na área e as suas características atuais, em um contexto de reestruturação produtiva.

\section{MATERIAL E MÉTODOS}

Sobre os levantamentos bibliográficos, este resumo trabalha com os conceitos de urbanização, industrialização, cidades médias, sobremodo, com base em autores Sposito (2004) e Lessa (2007). Na visita de campo foram aplicadas três entrevistas, com gerentes e administradores das indústrias BN Mascarenhas, Avanço distribuidora e 
Global Park, com o intuito de saber informações sobre as atuais características dessas indústrias/fábricas, o quadro de funcionários, a dinâmica das fábricas e o público que as constitui. Por fim, foi feita a sistematização das informações coletadas em campo, no qual foram criados gráficos, tabelas, quadros e mapas de fluxo, localização, todas indústrias cadastradas na FIEB em Feira de Santana, para interpretar sobre a implantação das indústrias/fábricas e como a economia do município se modificou com essas instalações.

\section{RESULTADOS E/OU DISCUSSÃO}

Em 2019, Feira de Santana possuía 767 indústrias cadastradas na Federação das indústrias do Estado da Bahia (FIEB). Dentre essas, estão as atividades ligadas à diversos ramos, como alimentício, vestimenta, metalúrgico, construção, instalação e manutenção e outros (mapa 1).

Mapa 1: Indústrias cadastradas na Federação das Indústrias do Estado da Bahia (FIEB) em Feira de Santana, 2020.

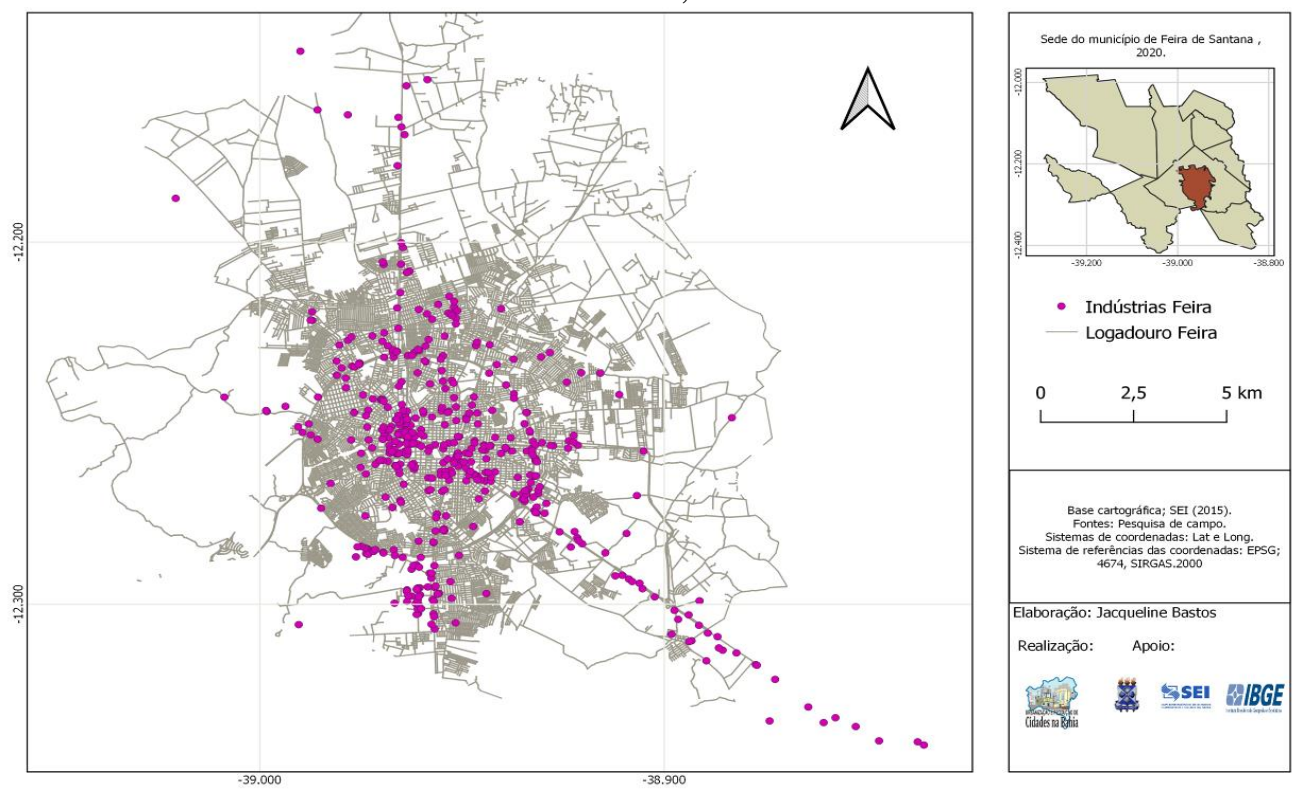

O Centro Industrial Norte (CIN) teve a implantação das suas primeiras indústrias no início da década de 2010, com construções de galpões com pouca infraestrutura, inicialmente. Hoje, possui cerca de 8 indústrias e fábricas em funcionamento mais efetivo, além dos galpões que ainda estão em construção, sendo as que possuem mais destaque: B.N Mascarenhas, Incomprel, Avanço Distribuidora e Globalpark, além de construções aceleradas de galpões para instalação de novas fábricas e indústrias na localidade na BR 116 norte, entre a Universidade Estadual de Feira de Santana (UEFS) e o Distrito de Maria Quitéria, então área rural.

Em relação as interações espaciais das indústrias estudadas do CIS Norte, foi notório que há um grande fluxo de matérias-primas advindas de locais externos. Já em relação à distribuição, muitas das vezes, estão restritas ao território estadual (mapa 2).

Outro fator de importância foi o incentivo municipal, porque houve para a criação de um novo Centro Industrial, sendo firmado com as Leis complementares de $\mathrm{n}^{\circ}$ 75, de 20 de junho de 2013, no título III, Art. $4^{\circ}$ e $5^{\circ}$, e a Lei complementar $N^{\circ} 86 / 2014$, que criou um novo bairro na cidade denominado CIS Norte, que abarca exatamente o local onde estão instaladas as indústrias, e a de ordenação do uso e ocupação do solo, que delimitou essa área como industrial, respectivamente (FEIRA DE SANTANA, 2013, 2014).. 
Ao analisar a origem e destino dos produtos que a indústria Avanço produz no CIS Norte, foi perceptível que eles vêm de municípios dos estados do Sul e Nordeste. Todavia, após o fabrico, os destinos dos mesmos se dão para municípios da Bahia, sendo uma indústria estadual, sem ligação externa de vendas.

Mapa 2: Origens dos produtos das indústrias do CIS Norte, Feira de Santana/BA, 2020

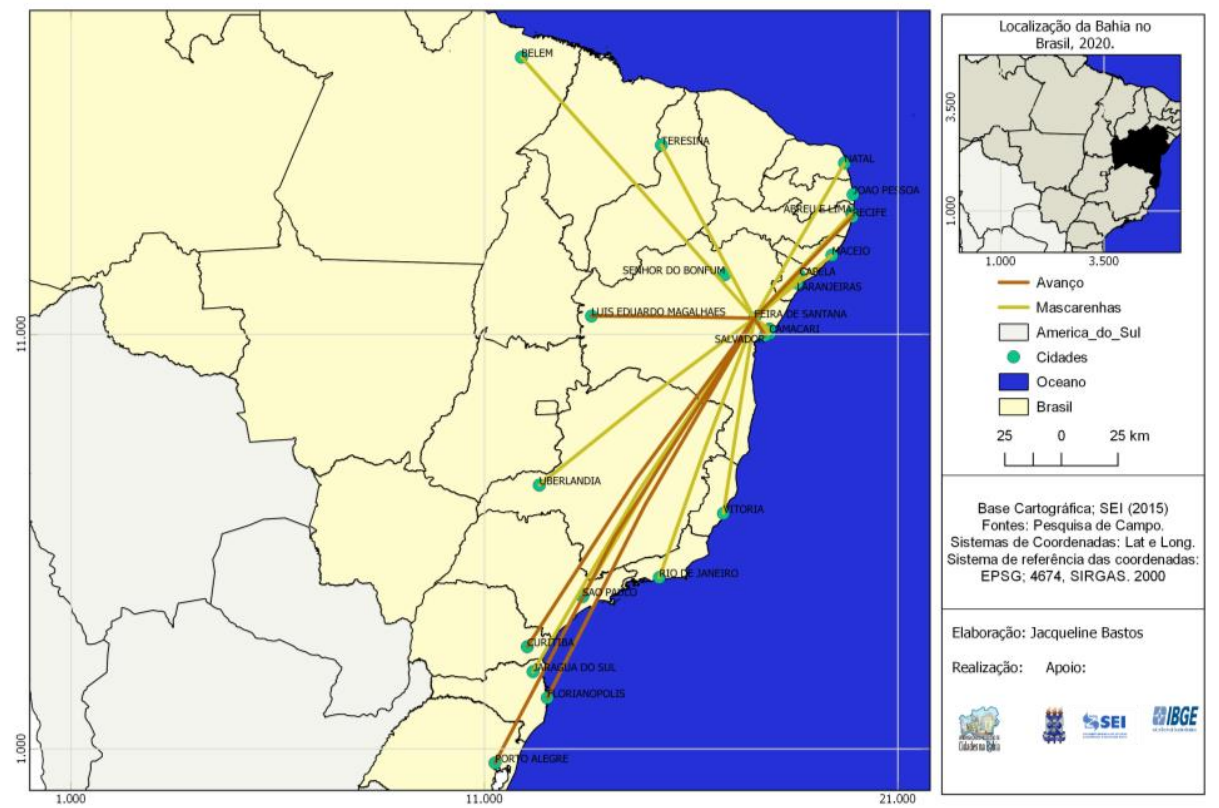

Ao que diz respeito a indústria $\mathrm{BN}$ Mascarenhas, a mesma se trata de uma indústria com mercado nacional e que tem suas vendas distribuídas em quase todas as regiões do Brasil. Os produtos utilizados nessa indústria vêm de todas as regiões do Brasil, com destaque para o Nordeste e Sudeste. Sobre o destino dos produtos, o mesmo não se restringe apenas na Bahia e é direcionado à diversos municípios dos estados do Norte, Nordeste e Sudeste.

Mapa 3: Origem dos funcionários das indústrias do CIS Norte, Feira de Santana/BA, 2020.
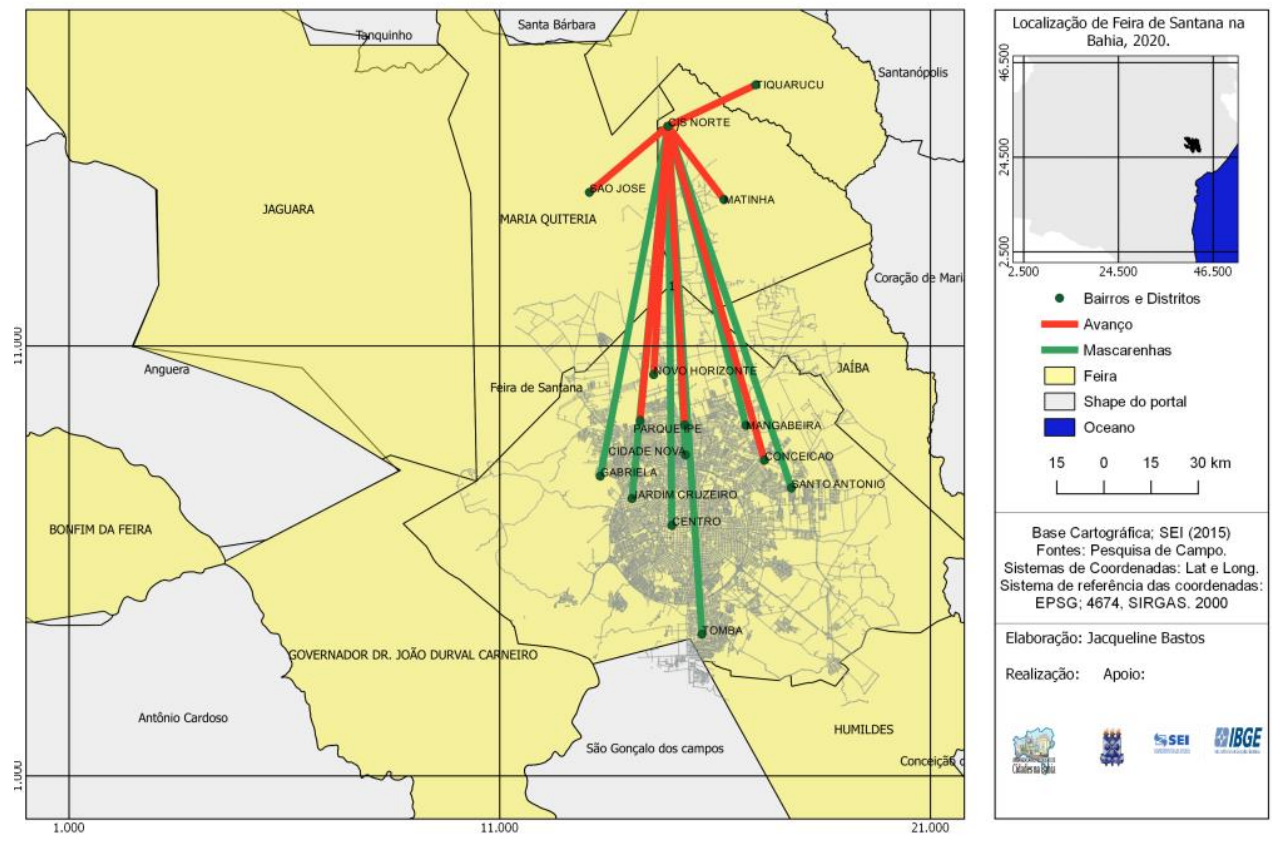
Em relação à origem dos funcionários dessas indústrias, as mesmas buscam empregar trabalhadores locais e quase todos são do município de Feira de Santana (Mapa 3).

\section{CONSIDERAÇÕES FINAIS}

Em relação a motivação que os representantes das indústrias tiveram para escolher tal área como a ideal para implantar sua unidade produtiva, os mesmos relataram que o motivo principal que os levou a instalar seus empreendimentos nesse local em específico foi a localização, sendo de total importância como facilitador do escoamento dos produtos.

Com base nos levantamentos bibliográficos e nos dados obtidos através das entrevistas e visitas de campo, verificou-se que com a chegada das indústrias/fábricas B.N Mascarenhas, Incomprel e Avanço Distribuidora na BR 116 norte ocasionaram como consequência certa valorização e intensificação das chegadas de novas indústrias.

Em consequência da duplicação da BR 116 Norte, ocorre a valorização maior ainda do solo no entorno das indústrias/fábricas, já que essas trouxeram mais investimentos de interesses industriais, o que fez surgir um segundo Centro industrial de relevância para o município de Feira de Santana.

É importante compreender que apesar do CIS Norte possuir características e infraestrutura parecida com o Centro Industrial Subaé (CIS), a mesma não possui relações físicas e econômicas com o município como era na década de 1970, já que o processo de reestruturação produtiva provocou mudanças nas relações tempo-espaço e na organização e funcionalidade das indústrias em determinado espaço.

\section{REFERÊNCIAS}

BRASIL. Lei complementar $N^{\circ} 75$, de 20 de junho de 2013. Dispõe sobre das criações de novos bairros. Disponível em: https://leismunicipais.com.br/a/ba/f/feira-desantana/lei-complementar/2013/8/75/lei- Acesso em: 20 Mai. 2020.

BRASIL. Lei complementar $N^{\circ} 86 / 2014$. Dispõe sobre ordenamento do uso e ocupação do solo. Disponível em: https://leismunicipais.com.br/a/ba/f/feira-de-santana/leicomplementar/2014/8/86/lei-complementar-n-86-2014-altera-modifica-amplia-e-danova-redacao-a-lei-n-1615-92-que-institui-a-lei-do-ordenamento-do-uso-e-da-ocupacaodo-solo-na-area-urbana-do-municipio-de-feira-de-santana-e-revoga-a-lei-complementarn-46-de-19-de-agosto-de-2010-que-dispoe-sobre-o-sistema-viario-das-areas-deexpansao-urbana-da-cidade-de-feira-de-santana. Acesso em: 20 Mai. 2020.

LESSA, Carlos. Política industrial e industrialização, Instituto de Economia da UFRJ, 2007. Disponível em: http://www.ie.ufrj.br/aparte/pdfs/lessa090507.pdf. Acesso em 20 de Out. 2018.

SPOSITO, Maria Encarnação Beltrão. Capitalismo e Urbanização. 14. ed. São Paulo: Contexto, 1994. 